\title{
REESCRITURA DEL MITO Y REPRESENTACIÓN DE LO FEMENINO EN LA NOVELA LES PRÉNOMS ÉPICÈNES (2018) DE AMÉLIE NOTHOMB
}

\author{
REWRITING MYTHS TO RE-THINK FEMININE ROLES LES PRÉNOMS ÉPICÈNES \\ (2018) BY AMÉLIE NOTHOMBS
}

Antonella Ippolito Speziale

\section{Resumen:}

La contribución analiza los mecanismos con los que Amélie Nothomb, en su novela Les prénoms épicènes (2018), establece un proceso de recombinación y reescritura a partir de diferentes formas de "mito". El relato convierte la relación explícita con la comedia Epicoene (1609) de Ben Johnson y el recurso al mito órfico en instrumentos de escenificación irónica de clichés asociados a la identidad femenina.

\section{Palabras clave:}

Mito, intertextualidad, postmoderno

\section{Abstract:}

The contribution analyzes the way Amélie Nothomb re-uses different forms of (literary as well as cultural) myths to in her novel Les prénoms épicènes (2018) through a process of deconstruction and re-combination of their constitutive elements. The intertextual relation to the Elizabethan comedy Epicoene (1609) and to the myth of Orpheus are used to ironically point at the many clichés related to female roles.

\section{KeYWORDS:}

estereotipos, Myth, intertextuality, clichés, postmodern 


\section{LA NOVELA LES PRENOMS EPICENES}

Epicenos son aquellos substantivos cuya forma masculina y femenina se designa por igual, sean éstos nombres comunes o propios, como Claude y Dominique, protagonistas de la novela homónima de Amélie Nothomb. Con este título la autora nos sumerge en una narración típicamente postmoderna que recupera y varía unos temas ya presentes, incluso tópicos en sus obras anteriores. Por tanto, junto al tema de la familia disfuncional y de la amistad se elabora la idea de éxito en la época del capitalismo industrial. Por otro lado, desde el punto de vista formal, el texto se constituye como un mosaico que recompone fragmentos de narraciones bíblicas, literarias y mitológicas, recontextualizados (a menudo en clave paródica) mediante procesos de duplicación, repetición y variación, rasgos típicos de la autora.

En una primera lectura, el libro desarrolla una historia algo sencilla y casi banal, ambientada en los años 70: por una parte, una relación malsana entre marido y mujer, en la que la esposa se niega a admitir la gravedad del comportamiento del cónyuge; por otra, una niña elaborando sus propias estrategias para sobrevivir al rechazo emocional de su padre ${ }^{1}$. Tras una breve escena dialógica, que desde el punto de vista del contenido resulta ajena a la narración siguiente, el verdadero relato se abre con la figura de Dominique, una chica no convencional para su época: de origen modesto, está feliz con su trabajo de secretaria, el cual le permitió independizarse económicamente y no le interesa ni la moda, ni la belleza, ni las relaciones amorosas. Sin embargo, su vida cambia cuando Claude, aparentemente el hombre perfecto, empieza a cortejarla. Claude consigue que Dominique se case con él, lo acompañe en París en su imparable ascenso social y que, tras mucho intentarlo, le dé una hija que se llamará Épicène; pero muy pronto, a pesar de ser hermosa y muy inteligente, la niña tendrá que resignarse al inexplicable odio de su padre e intentar protegerse de su influencia para no perderse en la infelicidad.

Un segundo nivel de lectura, pero aún a nivel de contenido, destaca el tema del engaño y de la intriga. En un montaje casi cinematográfico, a lo largo del texto se diseminan pistas que ayudan al lector a desentrañar poco a poco el misterio que esconde la historia. Y es que Claude, devorado por la ira tras una decepción amorosa, ha organizado toda su existencia alrededor de oscuros proyectos de venganza personal contra la mujer que lo abandonó, cuyo instrumento inadvertido sería otra mujer, aparentemente acomplejada y sin cualidades intelectuales para ser usada como él desee, pero lo suficientemente bella para aparecer en la sociedad (véase Nothomb, 2018: 109 ). El juego con el lector - cuyas expectativas se ven constantemente influenciadas, incluso de manera engañosa - se establece a partir de la escena introductoria con su

1 El tema ya aparece en Frappe-toi le cœur (2017), donde la figura negativa es la madre. 
carácter dialógico y su estructura anular marcada por la repetición del verbo décolérer al principio y al fin (Nothomb, 2018: 7 “Il ne décolère pas" - 11 "Il ne décolerera pas"). Aquí, una joven llamada Reine, tras una noche con su novio (la autora no desvela su nombre) le comunica su intención de casarse con otro, lo que le garantizaría una vida cómoda en París. En este sentido, se sugiere la idea de un personaje femenino frío y calculador, orientado al ascenso social a pesar de los sentimientos del amante devoto; sin embargo, a medida que la acción avanza y se revela la verdadera naturaleza de las relaciones entre los protagonistas, estas características resultan pertenecer al personaje masculino de la escena, que es el propio Claude.

La estructura narrativa de Les prénoms épicènes se encuentra caracterizada por la repetición diferencial de unos temas y motivos centrales, lo que también es un rasgo característico de la producción artística de la autora. Así asistimos a la puesta en abismo del tema de la amistad, primero a travès de Épicène y de su compañera de escuela Samia, luego a travès de Dominique y de Madame Cléry. Esta figura (cuyo nombre, Reine, plantea en el lector unas preguntas bien fundadas en relación a la escena inicial) aparece como la esposa de una persona importante con la que Claude pretende hacer negocios: cuando Épicène empieza a ir a un colegio elegante, Claude sugiere que Dominique se acerque a ella aprovechando que sus hijas asisten a la misma escuela.

La relación de Dominique con su amiga se desarrolla mediante la moda, de la que Madame Cléry es una experta. En este contexto se repiten las alusiones a la magia y a la seducción - que también había caracterizado el encuentro con Claude - a través del motivo del champagne (sean éstos "Reine procédait par la plus naturelle des magies ... débouchait une bouteille de champagne en disant que le Deutz était son thé préféré"; Nothomb, 2018: 95)² y la referencia explícita a la seducción por Claude como una experiencia similar (ibid.: "elle était séduite. Claude aussi l'avait séduite et elle avait adoré cela, qui avait duré quelques jours. Avec Reine, la séduction n'en finissait pas”).

De este modo, el texto sugiere un parecido que sólo es otra forma de engañar y sorprender al lector, ya que la amistad con Reine resultará ser sincera. El coche, el regalo exagerado y vistoso que esta última obsequia a Dominique, se convertirà en el instrumento de su liberación.

Un tercer nivel de significado - en nuestra opinión, el hilo conductor subyacente en el relato - es una deconstrucción irónica del tema de lo masculino y lo femenino. Se trata de un nivel más complexo que sólo se revela al lector "activo", capaz de cuestionar el significado y el valor de la intensa intertextualidad con la que Nothomb construye este cautivador relato. Una deconstrucción irónica de los estereotipos y

2 Nothomb retoma aquí el simbolismo de la burbuja de champán, ya decisivo para obras como Le fait du prince (2008) et Pétronille (2014). La burbuja funciona como un dispositivo textual que hace referencia a la magia, el sentimiento y la ebriedad. 
convenciones de género y, especialmente, de la forma tóxica en que estos actúan dentro de las relaciones, impregna totalmente la narración y merece un análisis que aún no se ha intentado. Para realizar esta operación, la autora recurre a la puesta en escena de diferentes modelos femeninos y masculinos, basada en el contraste entre pasividad y actividad, dependencia e independencia, a partir de la reinterpretación y del entrelazamiento de una serie de mitos, descompuestos en sus elementos constitutivos y hábilmente reposicionados en el tejido narrativo. Sin embargo, cuando hablamos de mitos, lo hacemos en el sentido más amplio de la palabra. Si bien la autora recurre abundantemente al mito clásico, su repertorio incluye no menos mitos literarios, así como una variedad de 'mitos contemporáneos', o sea símbolos y estereotipos culturales y sociales. La constante transformación y desmitificación - sólo aparentemente lúdica a las que la ficción somete este conjunto de reminiscencias ${ }^{3}$ arrastra al lector a un mundo de significados abiertos a la interpretación, lo que confiere al propio texto de Nothomb el valor ejemplar de un texto mítico. Estos aspectos merecen ser desarrollados con más detalle mediante una lectura crítica que analice atentamente la 'escritura-palimpsesto' de Les prénoms épicènes.

\section{EL MITO LITERARIO: EPICOENE, OR THE SILENT WOMAN (BEN JONSON, 1606) COMO INTERTEXTO PRINCIPAL}

El nombre de la protagonista efectúa un impacto inmediato de sugerencias pertinentes a su carácter emblemático (por ser un nombre común que se convierte en propio). Este primer y más obvio mecanismo 'mitográfico' también revela la estructura intertextual de la novela, ya que establece una relación con un modelo preciso, es decir, la comedia en prosa Epicane, or the silent woman $(1606)^{4}$ de Ben Jonson. La razón por la que la protagonista se llama Épicène es explicada por Claude en la página 39 en respuesta a la observación de su esposa sobre la ambivalencia de sus propios nombres. Claude es el primero en definirlos prénoms épicènes añadiendo la mención explícita del dramaturgo isabelino, lo que indica el papel central de esta referencia: "Ben Jonson, un célèbre contemporain de Shakespeare, a donné ce titre à l'une de ses pièces. Il en fait le nom de la femme parfaite" (Nothomb, 2018, p. 39). No es éste el lugar para tratar con

3 Los relatos de Nothomb contienen toda una serie de alusiones más o menos aparentes; el grado de evidencia que se da a las diversas alusiones es variable, así como la distancia irónica y/o subversiva que emerge en el texto. Cfr. Constant, Isabelle (2003). Construction hypertextuelle : "Attentat" d'Amélie Nothomb. The French Review, 76/5, pp. 933-934; Oberhuber, Andrea (2004). Réécrire à l'ère du soupçon insidieux : Amélie Nothomb et le récit postmodeme, Études françaises, 40(1), 111-128. El resultado, según Yolande Helm, es una empresa de "desacralización" de la recepción y producción literaria y del mito en general. La densa red de referencias se alimenta de los estudios filosóficos y filológicos de la autora, pero también mezcla cultura "alta" y el entretenimiento pop; vid. Helm, Yolande (1996). Amélie Nothomb : $1^{\prime}$ «enfant terrible» des lettres belges de langue française. Études francophones, 11(1), 120.

4 Representada en 1609 e impresa en 1616, la pièce tal vez fue juzgada como la más perfecta comedia inglesa. 
detalle esta obra, que fue de las más populares de Jonson; no obstante, para nuestro discurso cabe observar que la intriga que su compleja trama plantea toca unos temas cruciales de la novela y nos hablan de una sociedad en la que el papel de la mujer era realmente frágil y sus oportunidades dependían de un posible matrimonio. A partir de la combinación de dos chanzas de origen griego (una de las cuales se encuentra en la Casina de Plauto) el argumento plantea una variación sobre el motivo del hombre inducido a casarse por engaño con una mujer que, como resultará al final, en realidad es un hombre adiestrado a tal efecto. Así, a través del motivo central del engaño, del disfraz y de la sustitución se abordan temas significativos de acuerdo con los patrones culturales de la época: el matrimonio, la virtud femenina y la esposa perfecta. Según se alterna la perspectiva entre unos y otros personajes, el matrimonio se presenta como solución o como problema. Según el personaje principal, perfecta significa sumisa y silenciosa como tal vez ni siquiera exista, ya que las mujeres serían generalmente ruidosas y prepotentes. En este sentido, la comedia también contiene una referencia al estereotipo satírico caracterizando a la mujer instruida como un monstruo y un peligro para los hombres 5 .

A la virtud deseable en una mujer se refieren varios personajes. En la broma, en la que un sobrino quiere impedir el matrimonio de su tío rico que le dejaría sin la herencia, la supuesta novia Epicœne (es decir, el muchacho disfrazado) inmediatamente después del matrimonio se revela muy parlanchina, de modo que el marido quiere deshacerse de ella y busca la manera de solicitar el divorcio. Para arreglar las cosas, dos personajes afirman haber tenido relaciones con Epicœne, lo que la haría 'despreciable'. Por lo tanto, la virtud femenina depende de los hombres para ser confirmada o negada.

En Les prénoms épicènes, la relación con la comedia de Ben Jonson, ya entrevista en Pétronille (2014), se refleja a diferentes niveles e implica una inversión de sabor irónico. Al igual que Morose, el protagonista de Epicoene, Claude busca una "mujer silenciosa" para llevar a cabo su venganza y elige a Dominique porque la considera indebidamente una persona sosa y anodina ( “J'ai choisi ma femme parce qu'elle n'existe pas [...] Cette femme n'est rien. [...] Je l'ai choisie parce qu'elle était assez belle pour jouer les femmes du monde et assez complexée pour que j'en fasse ce que je voulais"; Nothomb, 2018, p. 109). Jonson, señala Claude, hace de Epicoene "le nom de la femme parfaite" (ibid.), pero el sentido de tal perfección se le volverá en contra: su hija Épicène demostrará ser realmente la mujer perfecta, pero no por su silencio, sino por su capacidad de remontar y erigirse como dueña de sus emociones, de su libertad y de su autonomía personal hasta desmarcarse definitivamente de él. La perfección de Épicène consistirá en sacar su fuerza de la ambivalencia que su nombre señala. Al igual que la Epicoene

$5 \quad$ En la comedia, el grupo de las Collegiate Ladies y la figura de Mrs. Otter encarnan la asociación entre las características negativas atribuidas a las mujeres y la pasión por el estudio. 
de la comedia, la chica sabrá interpretar un doble papel - masculino y femenino - para lograr una venganza exitosa, que es, precisamente, lo opuesto a la fracasada venganza planteada por su padre. Además, también está presente una alusión al motivo paródico de la mujer instruida, cuyo valor negativo se refleja en la figura cómica de la gorda profesora de latín Madame Caracala ${ }^{6}$ y encuentra su contraparte en la propia Épicène, una estudiante brillante que encarna un modelo positivo de mujer culta.

\section{LOS CLICHÉS DE LO COTIDIANO A TRAVÉS DEL FILTRO DEL IMAGINARIO LITERARIO: CHANEL № ${ }_{5}$ COMO DISPOSITIVO DE LA SEDUCCIÓN}

El recurso a clichés facilmente identificables es un elemento esencial del relato. Al comienzo de la historia, la construcción del personaje de Claude como el novio ideal se nutre de fórmulas convencionales, de un lenguaje estereotipado cargado de lugares comunes y de una gestualidad correspondiente a ésos. La oferta de un champagne (por supuesto, un champagne muy caro) es la primera frase con la que Claude se dirige a Dominique (Nothomb, 2018, p. 12); sin embargo, no escucha lo que dice Dominique (ibid.) y la felicita por su aspecto físico con un lenguaje también estereotipado ("vous êtes ravissante, Dominique" [...] "vous n'êtes pas de celles qu'on oublie"; Nothomb, 2018 , p. 15). Lo mismo ocurre con la propuesta de casarse ("Dominique, acceptezvous de devenir ma femme? [...] Au premier regard, j'ai su que vous étiez celle que je cherchais"; Nothomb, 2018, p. 17). En este sentido no sorprende que Nothomb se decante por el campo metafórico de la caza para representar alusivamente la petición de matrimonio como una acción de conquista ${ }^{7}$, cuya percepción suscita en Dominique sentimientos conflictivos entre perplejidad y miedo ("elle éprouva la joie du gibier victorieux"; Nothomb, 2018, p. 18). La situación llega a un punto de inflexión cuando Claude decide comprarle a su novia un perfume de lujo. La vendedora se da cuenta de que delante de ella no hay un hombre enamorado, sino un presuntuoso que ni siquiera conoce a la destinataria del regalo y sólo pretende impresionarla con un símbolo de prestigio, y se venga recomendándole al cliente un producto que, por ser el cliché de los clichés, debería ponerla en guardia ante el peligro: Chanel no 5 .

Al probar el perfume, Dominique se siente completamente abrumada por él, entrando en un estado de intoxicación casi erótica: en una escena clave, se desnuda completamente para aplicarlo a su piel, que aparecerá transformada al efecto de la fragancia ("[...] elle porta à ses narines sa peau metamorphosée par l'onction [...]";

6 En la obra de Amélie Nothomb, la obesidad es un elemento típico que caracteriza a muchos personajes negativos, como Prétextat Tach en Hygiène de l'Assassin (1992) y Bernadette en Les Catilinaires (1995).

7 Cfr. Nothomb, 2018, p. 17: “quand vous m'aurez épousé, vous n'aurez d'autre choix que d'y (=à Paris) habiter". 
Nothomb, 2018, p. 29). Cabe destacar que el término unción proporciona a la acción una connotación sacra, reconocible en otro lugar a nivel léxico ("le dieu du parfum"; Nothomb, 2018, p. 30). Asimismo, Dominique vive una situación de éxtasis en la que el perfume se convierte en un Ersatz del hombre como objeto de amor ("l'objet lui parut d'une beauté inégalable"; Nothomb, 2018, p. 28): a través del regalo, se convence de que ama a Claude y acepta casarse con él. El perfume de lujo como 'mito de lo moderno' adquiere así una función de dispositivo textual marcado por una fuerte ambivalencia: por un lado se refiere, simbólicamente, al papel femenino al que Claude pretende empujar a Dominique, mientras que por otro lado encarna también el potencial seductor de la figura masculina, la sexualidad y el despertar del deseo. En este momento, hay una proliferación de alusiones a la tradición del mito clásico y del cuento de hadas. Así, el uso agudo e irónico del verbo stupéfier, que indica maravilla, pero también el efecto de drogas, conjura el motivo de la poción amorosa ("1'odeur la stupéfia trop profondément pour qu'elle puisse savoir si cela lui plaisait"; Nothomb, 2018, p. 29). La fragancia disipa los miedos y las dudas haciendo que Dominique se sienta como una reina (ibid: "elle aurait dit que cela sentait la reine d'un autre monde"), cuyo noble libertador será Claude ("ce prince qui la délivrerait du sortilège qui l'emprisonnait"; Nothomb, 2018, p. 31). Incluso el clásico beso se convierte en una experiencia olfativa: Chanel no 5 es "la beauté enfin encarnée et le baiser de ses rêves" (Nothomb, 2018, p. 29).

Asimismo, la escena conlleva una reminiscencia literaria específica. Los gestos de Dominique aplicando el perfume recuerdan uno de los episodios más famosos de la Metamorfosis de Apuleyo, y precisamente la transformación de la maga Pánfila en un ave nocturna a merced de un ungüento mágico, que llevará al protagonista y narrador Lucio a ser convertido en asno por desear hacer lo mismo, pero con el ungüento equivocado. El juego intertextual subvierte el modelo en la medida en que 'desplaza' sus motivos estructurantes, otorgándole a Dominique, al mismo tiempo, los roles de ambos personajes del relato apuleyano - una vez más, con un efecto irónico. Dominique se imagina a sí misma alzando el vuelo como la maga Pánfila. Sin embargo, su porvenir se aproximará más al de Lucio, al embadurnarse, si no con el ungüento equivocado, al menos con aquel que la persona equivocada (y por las razones equivocadas) le trae. El Chanel $n^{\circ} 5$ no es el regalo de un amante, sino el de un manipulador, y el encantamiento que opera es totalmente 'maléfico'. Como Lucio en asno, Dominique queda convertida en algo diferente de lo que es. Si al principio de la historia casi no se considera una chica 'normal' (véase Nothomb, 2018, p. 14), a partir de ese momento empieza a pensar y actuar como una mujer-estereotipo. Así, cuando su colega intenta avisarla acerca de Claude, ella lo interpreta como envidia ("jalousie"; Nothomb, 2018, p. 31) y sueña con París como la ciudad en la que "de telles mesquineries n'existaient pas"; renuncia a su trabajo y solo apoya y elogia los éxitos de Claude; frente a su autoritaria exigencia 
de que le diera hijos, ella acepta y se siente culpable por el retraso del embarazo, justificando los reproches de su marido con decir que "la haine est proche de l'amour" (Nothomb, 2018, p. 36). Así se describirá la transformación de Dominque a través de los ojos de su hija Épicène: "Bizarrement, maman aimait papa... cela se voyait, se sentait, s'entendait. Maman avait pour s'adresser à papa une voix pleine de déférence, des yeux intenses et des gestes choisis" (Nothomb, 2018, p. 51).

\section{EL INTERTEXTO MÍTICO: ORFEO Y EURÍDICE}

4.1. UNA VOZ PARA EURÍDICE: EL MITO ÓRFICO COMO REFERENCIA INSPIRADORA EN LA OBRA NARRATiva de AmÉlie Nothomb

La escritura de Amélie Nothomb ha sido descrita por Yolande Helm como "une écriture alimentée à la source de l'orphisme", debido a la importancia del rol que el mito de Orfeo desempeña en sus obras y que ha sido investigado sobre todo a partir de su primer relato, Hygiène de l'assassin (1992) ${ }^{8}$. Un paralelismo entre los personajes femeninos y la figura de Eurídice se establece frecuentemente a través de los motivos básicos elaborados en las tramas de las novelas, como en el caso, entre otros, de Mercure $(1998)^{9}$. Además, Nothomb parece reconstruir el mito de Orfeo a su manera, creando en sus novelas una estructura que destaca a la figura de Eurídice para darle voz y vida $^{10}$; «une écriture qui puisse redonner vie à Eurydice », como la propia autora ya declaró en 1997 en una carta citada por Yolande Helm (Helm, 1997, p. 51). Por lo tanto, no es sorprendente la relevancia del arquetipo órfico en Les prénoms épicènes. Una vez más, como en novelas anteriores, la autora transfiere a sus protagonistas los rasgos característicos de las figuras del mito, lo que implica la deconstrucción de su tradición dentro del paradigma patriarcal y produce una reinterpretación subversiva ${ }^{11}$, sobre todo en relación con la identidad fantasmal del personaje de Eurídice.

La reelaboración literaria del mito desde esta perspectiva encaja en una evolución que forma parte de las tendencias literarias del siglo $\mathrm{XX}$ y que ha sido relacionada - en lo que concierne a la literatura francesa - con el momento en que la influencia

8 Helm, Yolande (1997). Amélie Nothomb: une écriture alimentée à la source de l'orphisme. Réligiologiques, 15, 151-163, especialmente pp. 152-153.

9 Cfr. Marois, Laurence (2011). Le double mythique : la figure d'Eurydice dans Mercure d'Amélie Nothomb", Revista de mitocrítica, 3, pp. 73-93.

10 Cfr. Benali, Souad (2009). Le personnage féminin en difficulté. Cas d'étude: les romans d'Amélie Nothomb. Les cahiers du CRASC, 20, pp. 41-52.

11 Cfr. Amanieux, Laureline (2009). Le récit siamois. Identité et personnage dans l'œuvre d'Amélie Nothomb, Albin Michel, 2009, 145-156; Ribarova, Pavlina (2013). Dimensions mythologiques des romans d'A. Nothomb: Mythifier, demythifier et remythifier. Bulgaria Research Papers, 51/1 (2013), p. 197. 
del pensamiento psicanalítico freudiano penetra en Francia ${ }^{12}$. Reescrituras como la de Marguerite Yourcenar en La Nouvelle Eurydice (1931), el drama Eurydice (1963) de Jean Anouilh, las novelas de Michèle Sarde Histoire d'Eurydice pendant la remontée (1979) y de Sylvie Germain L'enfant Méduse $(1991)^{13}$ muestran cómo la atención de los escritores se aleja de Orfeo para dirigirse a Eurídice y al tema (cada vez más central) del descenso a los infiernos.

De hecho, si consideramos la historia tal y como las fuentes nos la han transmitido, vemos que Eurídice parece no tener un carácter propio y quedarse escondida detrás del de Orfeo. Las dos versiones más conocidas del mito, la de Virgilio y la de Ovidio, subrayan este aspecto a la vez que acentúan el cariz sentimental de la historia que de tanta fortuna gozará en la literatura y la música. Eurídice se caracteriza principalmente por el anonimato y la indeterminación: no parece tener un carácter propio e incluso su nombre no siempre se transmite de manera unívoca ${ }^{14}$. Su existencia casi empieza en el momento en que se muere, destinada a permitir el descenso de Orfeo al averno y a destacar su talento poético y musical. Para ella, la mirada del propio Orfeo será fatal, porque nunca le permitirá cruzar el ambiguo umbral entre vida y muerte. Nunca habla: sólo en el relato virgiliano, cuando Orfeo se vuelve para mirarla, lamenta que su furor destruya en un momento la felicidad nada más recuperada (Georg. IV, 494495: “Quis et me, inquit, miseram et te perdidit, Orpheu, quis tantus furor?"). Ovidio ni siquiera le permite esta actitud: al presentarla una vez más en función del amor que Orfeo le tiene, sólo le hace decir la palabra "adiós” comentando que Eurídice no tendría motivos para quejarse de un error cometido por amor (Met. X, 60-61 “iamque iterum moriens non est de coniuge quicquam / questa suo (quid enim nisi se quereretur amatam?)". En una palabra, sólo existe el 'mito de Orfeo y Eurídice', pero no un 'mito de Eurídice'.

\subsection{Comment deVenir un Orphée moderne? El tratamiento creativo del modelo anti- GUO EN LES PRÉNOMS ÉPICÈNES}

Retomando el término acuñado por Lévi-Strauss, en el conjunto narrativo de Les prénoms épicènes se encuentran varios mitemas que señalan una recuperación del mito

12 Kushner, Eva (1961). Le mythe d'Orphée dans la littérature française contemporaine, A. G. Nizet, p. 348.

13 Cfr. Bouloumié, Arlette (2004, Enero). La résurgence du mythe d'Eurydice et ses métamorphoses dans l'oeuvre d'Anouilh, de Pascal Quignard, de Henri Bosco, de Marguerite Yourcenar, de Michèle Sarde, et de Jean-Loup Trassard. Loxias - Revue des centres de recherche pluridisciplinaires, 2, http://revel. unice.fr/loxias/document.html?id= 1244 .

14 Cfr. Béague, Annick, Boulogne, Jacques, Deremetz, Alain, y Toulze, Françoise (1998). Les visages d'Orphée, Presses universitaires du Septentrion, p. 49. La primera mención se encuentra en el poeta helenístico Hermesianacte de Colofón (III s. a. de C.); sin embargo, hay fuentes donde se registra el nombre de Argiope/Agriope. Cfr. Heurgon, Jacques (1932). Orphée et Eurydice avant Virgile. Mélanges d'archéologie et d'histoire, 49(1), p. 15. 
de Orfeo y Eurídice. Primero, el cruce del río como frontera entre dos mundos. La niña Épicène cruzando a la otra orilla del Sena para volver a ver a su mejor amiga Samia es explícitamente asociada con Orfeo, con el cual ella se identifica. Cuando Claude pone fin a una amistad socialmente indecorosa con unos comentarios racistas que alejan a Samia definitivamente, su gesto cruel actúa como el decreto infernal que marca la separación final de las chicas. Por otro lado, es precisamente la figura de Claude la que se asocia con el otro mitema de la mirada dañina y mortal. Su primer encuentro con Dominique nos lo muestra como el hombre que "à la table voisine, la contemplait d'un regard fixe" (Nothomb, 2018, p. 12). Es precisamente este "regard fixe" lo que la confinará en años de pasividad similar a la de Eurídice entre los muertos, quizá superponiendo a la reminiscencia de Orfeo otra alusión mitológica a la mirada petrificante de Medusa. En esta etapa se le atribuyen a Dominique las reacciones emocionales típicas de las mujeres sumisas que justifican a sus compañeros abusadores, como la idea de un 'cambio' del marido determinado por las responsabilidades laborales asumidas para lograr un éxito del que la esposa es la partidaria y la fiel colaboradora: "Il n'y a rien a regretter [...]. Il faut se réjouir de son succès dont il est fier [...]. Il a voulu tout ça et il m'a choisie pout etre à ses cotés" (Nothomb, 2018, p. 46) ${ }^{15}$.

La estructura centrada en los personajes de Épicène y Dominique, hace que ambas figuras asuman, en momentos diferentes, tanto las connotaciones de Orfeo como las de la propia Eurídice. De esa forma, Amélie Nothomb establece un paralelismo entre los personajes femeninos y los del mito órfico imponiendo diferentes fenómenos de transformación en los motivos estructurantes del mismo. En este contexto, el argumento desarrolla ampliamente el mitema del descenso a los infiernos. Cuando Dominique, después de la revelación del engaño, 'despierta' y deja París llevándose a su hija, su viaje se caracteriza como una verdadera ascensión, no sólo geográfica. La mujer resurge del inframundo en el que el proyecto de Claude la encarceló, representado, en su forma más inmediata, por los roles convencionales y pasivos que recuerdan la inercia fantasmal de Eurídice en los relatos antiguos. Varios elementos hacen que el tejido mitológico clásico aflore en el texto; por ejemplo, la impresión que Épicène siente de despertarse de "un sommeil mortifère de plusieurs siècles" (Nothomb, 2018, p. 117), reiterada por la voz narradora con referencia explícita al Inframundo, o el motivo de la luz directamente asociado a la llegada a Brest (ibid.: "Dominique gara la voiture devant la maison de ses parents. Il y avait de la lumière").

Por lo tanto, Dominique encarna las funciones de Orfeo en un doble nivel: es decir, en relación a sí misma, pero también a Épicène, quitándosela a su padre-Plutón. Por su parte, tras llegar a Brest, Épicène se convierte en Orfeo para su madre, pues la ayuda

15 No sorprende que la escena termine con Dominique refugiándose en la autoilusión que encarna el perfume: "s'isolait parfois avec le flacon de Chanel n. 5 qu'elle n'osait plus porter. Et respirait le parfum du temps où l'amour l'éniorait" (Nothomb 2018: 46). 
a superar la última de sus actitudes pasivas solicitando el divorcio. También cabe destacar el papel importante del coche, ya que acordarse por fin de saber conducir significa para Dominique redescubrir la posibilidad olvidada de ser independiente ("Tu conduis bien, maman. Je ne savais pas que tu avais le permis. - Je l'avais oublié"; Nothomb, 2018, p. 117). Se observará que la autora manipula aquí otro mito, pero moderno y comercial: el coche, que como estereotipo publicitario asocia la libertad y la conquista al género masculino, y que se convierte en el instrumento que garantiza la liberación de las mujeres.

En este sentido, las figuras de Dominique y Épicène plantean por un lado una Eurídice pasiva como la del mito tradicional; por otro lado, construyen al mismo tiempo una nueva figura participando en el poder de Orfeo, capaz de sobrevivir a su mirada mortal. La narración se basa en una serie de estrategias de duplicación y multiplicación, en las que el papel de los diferentes personajes del mito se fragmenta y se refleja en los de la historia. Un juego de reflejos que se hace más complejo en el caso del personaje de Épicène, en correspondencia con la ambivalencia que indica su nombre. Ya se ha comentado que Épicène, a pesar de los rasgos que comparte en la ficción narrativa con la figura de Eurídice, ya de niña se identifica expresamente con Orfeo (Nothomb, 2018, pp. 59-61). Por un lado, encarna a Eurídice resurgida de sus años parisinos y de la "estrategia del celacanto" con la que logró escapar a la influencia nociva de su padre silenciando sus sentimientos. Por otro lado, una vez en Brest, se transforma en un Orfeo capaz de devolver la vida a su madre y a ella misma. Pero la identificación con el carácter masculino del mito aparece incluso antes. Particularmente interesante en este sentido es la discusión entre Épicène y su amiga Samia sobre la historia de Orfeo que acaban de estudiar en clase (Nothomb, 2018, pp. 59-61). Épicène, que está a punto de trasladarse a la Rive Gauche, asocia inmediatamente la imagen del río infernal Estigia con el Sena. Las niñas se preguntan entonces cuál de ellas es Orfeo y cuál Eurídice. Inicialmente es Samia quien se ve a sí misma como Orfeo, porque está dispuesta a ir a visitar a Épicène ( "Je viendrais te voir"; Nothomb, 2018, p. 67). Sin embargo, Épicène reclama el papel de Orfeo para sí misma y lo de Eurídice para su amiga, pero por otras razones. En particular, le atrae la figura del mítico cantor como el soberano por excelencia de la palabra poética ${ }^{16}$, cuyo poder principal consiste en manejar magistralmente el lenguaje, ya sea literario o musical hasta "ser en mismo tiempo el poema, la música y el texto" (cfr. Nothomb, 2018, p. 62); encarnación perfecta de una magia transmisible casi por contaminación, en un pasaje que invierte irónicamente la célebre imagen platónica del poeta-imán ${ }^{17}$ y configura el efecto de la poesía como epidemia (ibid.). Más interesada en este aspecto del mito que en su lado

16 Vid. Kushner, Eva (1961). Le mythe d'Orphée dans la littérature française contemporaine. A. G. Nizet, p. 74.

17 La referencia es al Ion, 533d-534a. 
sentimental, Épicène se plantea entonces la cuestión de cómo convertirse en "un Orfeo moderno", ya que es precisamente su papel de cantor el que permite al héroe atravesar el inframundo y quebrantar sus leyes (Nothomb, 2018, p. 60). Por consiguiente, como adolescente y luego como adulta, Nothomb nos la representa en el acto de contemplar los instrumentos lingüísticos, intentar dominarlos, apropiarse de un idioma (en este caso el inglés), e incluso reconocerse en él: en este sentido, dirá del verbo to crave, el tema de su tesis doctoral: "Ce verbe, c'est moi" (Nothomb, 2018, p. 137). Un verbo que debe entenderse más allá de la relación de su significado con la trama del relato, es decir, más allá de la referencia a la necesidad emocional del personaje-Épicène al que su padre nunca hizo caso. To crave esconde un sentido autorreflexivo como una alusión a la necesidad de expresión y creación artística. La figura de Épicène afirmando "Ce verbe, c'est moi" parece confirmar que el lenguaje, para Amélie Nothomb, es una omnipotencia par excellence, un instrumento personificado en el que la autora, a través de sus personajes, expresa una profunda confianza. Mediante la conquista del lenguaje, el personaje femenino Épicène se apodera de cualidades propias del poeta y, en un sentido autorreflexivo, de los escritores. Es, en definitiva, la palabra el instrumento que permite a Eurídice 'convertirse en Orfeo' al liberarse del inframundo y recuperar su autonomía.

4.3. TUer le PÈre: El SACRIficio RITUAL De Un Orfeo derrocado

Pero esto requerirá un acto definitivo de destitución del Orfeo original. Sorprendentemente para el lector, una forma de auto-identificación con el signo lingüístico también se produce en Claude. Enfermo terminal, durante su último encuentro con su hija comentará, tras aprender la traducción de to crave, "avoir un besoin éperdu de": "C'était le verbe de ma vie et je ne le connaissais pas" (Nothomb, 2018, p. 141).

Padre e hija se descubren similares en la necesidad desesperada de algo que para Épicène ha permanecido sin nombre, mientras que para el padre se identifica con su amante perdida (Nothomb, 2018, p. 145). Cuando Épicène pone fin a la vida de Claude quitándole el respirador sin premeditación, es como si finalmente silenciara una parte de sí misma.

Pero también cabe tener en cuenta que ya al principio de la novela, a través del motivo del perfume, Claude ha sido presentado en el signo del encantamiento y del hechizo. Su lenguaje cautivador, pero lleno de clichés, es la herramienta encantadora de un Orfeo en negativo; un Orfeo masculino, fracasado, y ahora agotado por un gesto ritual de sacrificio restaurando un orden liberador. El acto final remite así a lo que Yolande Helm define como paradigma fundamental del mito órfico: "la créativité via l'absence, la mort de l'autre" (Helm, 1997, p. 160), un paradigma ya claramente 
ilustrado en Hygiène de l'assassin (1992). Ahora la autonomía de Dominique y Épicène puede comenzar definitivamente, en un universo femenino en el que Claude se revela como la verdadera "tercera persona": “C'était Claude, la tierce personne”.

\section{CONCLUSIONES}

Con Les prénoms épicènes, Amélie Nothomb ha construido un relato que dibuja el contraste entre mujeres fuertes, que luchan para sobrevivir ante relaciones de abuso, y hombres que creen tener un poder psicológico y material, pero que no saben hasta qué punto pueden resultar prescindibles actores secundarios. Para representar esto, la escritora parece operar a través de la recuperación y deconstrucción de modelos literarios, cuyos fragmentos recompone en un marco que incluye su propia experiencia, personalidad y filosofía. Las referencias míticas y la red intertextual tejida por el texto actúan de forma subversiva y provocadora para responder a los conflictos existenciales típicos del mundo contemporáneo. En este sentido, en Les prénoms épicènes se produce una inversión sistemática del relato canónico del mito de Orfeo y Eurídice. Las características de Orfeo, un personaje masculino, como poseedor de un poder se transfieren a los personajes femeninos de la novela. A través de estos múltiples procedimientos, el juego literario de Nothomb induce a cuestionar los modelos sociales adquiridos. La intertextualidad y el juego de las reminiscencias se convierten en los instrumentos de una escritura-símbolo que arrastra al lector al 'hechizo' proveniente del lenguaje como herramienta omnipotente. La literatura se convierte así en una escritura femenina de doble filo, ya que, divirtiendo al lector, le lleva a plantearse problemas sin influir en él, pero fomentando la lectura como una experiencia activa de 'co-construcción' de significados.

\section{REFERENCIAS BIBLIOGRÁFICAS}

\section{FUENTES PRIMARIAS}

Jonson, Ben (1976). Epicœne or the silent woman (1609), ed. R. Holdsworth. Bloomsbury. Nothomb, Amélie (1992). Hygiène de l'assassin. Albin Michel.

Nothomb, Amélie (1995). Les Catilinaires. Albin Michel.

Nothomb, Amélie (2003). Attentat. Albin Michel.

Nothomb, Amélie (2008). Le fait du prince. Albin Michel.

Nothomb, Amélie (2014). Pétronille. Albin Michel.

Nothomb, Amélie (2017). Frappe-toi le cour. Albin Michel.

Nothomb, Amélie (2018). Les prénoms épicènes. Albin Michel. 


\section{FuENTES SECUNDARIAS}

Amanieux, Laureline (2002). La présence de Dionysos dans l'oeuvre d'Amélie Nothomb. Réligiologiques, 25, 131-146.

Amanieux, Laureline (2009). Le récit siamois. Identité et personnage dans l'œuvre d'Amélie Nothomb. Albin Michel.

Béague, Annick, Boulogne, Jacques, Deremetz, Alain, y Toulze, Françoise (1998). Les visages d' Orphée. Presses universitaires du Septentrion, 1998.

Benali, Souad (2009). Le personnage féminin en difficulté. Cas d'étude: les romans de Amélie Nothomb. Les cahiers du CRASC, 20, 41-52.

http://cahiers.crasc.dz/pdfs/n_20_benali.pdf

Bouloumié, Arlette (2004, Enero). La résurgence du mythe d'Eurydice et ses métamorphoses dans l'oeuvre d'Anouilh, de Pascal Quignard, de Henri Bosco, de Marguerite Yourcenar, de Michèle Sarde, et de Jean-Loup Trassard. Loxias - Revue des centres de recherche pluridisciplinaires, 2.

http://revel.unice.fr/loxias/document.html?id=1244

Constant, Isabelle (2003). Construction hypertextuelle: "Attentat" d'Amélie Nothomb. The French Review, 76(5), 933-940. http://www.jstor.org/stable/3133231

Dewez, Nausicaa (2003). L'Immortalité par la mort. Le mythe d'Orphée dans l'œuvre d'Amélie Nothomb. Lettres romanes, 57(1-2), 127-138. DOI: 10.1484/J.LLR.3.70

Helm, Yolande (1996). Amélie Nothomb: 1’ «enfant terrible» des lettres belges de langue française. Études francophones, 11(1), 113-120.

Helm, Yolande (1997). Amélie Nothomb: une écriture alimentée à la source de l'orphisme. Réligiologiques, 15, 151-163.

Heurgon, Jacques (1932). Orphée et Eurydice avant Virgile. Mélanges d'archéologie et d'histoire, 49(1), 6-60.

Kushner, Eva (1961). Le mythe d'Orphée dans la littérature française contemporaine. A. G. Nizet.

Marois, Laurence (2011). Le double mythique : la figure d'Eurydice dans Mercure d'Amélie Nothomb. Revista de mitocritica, 3, 73-93. DOI: 10.1891/0886-6708.5.2.119

Oberhuber, Andrea (2004). Réécrire à l'ère du soupçon insidieux: Amélie Nothomb et le récit postmodeme. Études françaises, 40(1), 111-128. DOI: 10.7202/008479ar

Ribarova, Pavlina (2013). Dimensions mythologiques des romans d'A. Nothomb: Mythifier, demythifier et remythifier. Bulgaria Research Papers, 51(1), 193-205. 